\title{
Highly pathogenic avian influenza H5N1 virus could partly be evacuated by pregnant BALB/C mouse during abortion or preterm delivery
}

\author{
Lili Xu ${ }^{1,2 \dagger}$, Linlin Bao ${ }^{1,2 \dagger}$, Wei Deng ${ }^{1,2}$ and Chuan Qin ${ }^{1,2^{*}}$
}

\begin{abstract}
The highly pathogenic avian influenza H5N1 virus is one of candidates for future pandemic. Since H5N1 viruses had previously been isolated only from avian species, the outbreak raised questions about the ability of these viruses to cause severe disease and death in humans. Pregnant women are at increased risk for influenzaassociated illness and death. However, little is known about whether influenza viruses could transmit to the fetus through the placenta, and the effects of abortion and preterm delivery to maternal influenza infection are not well understood. We found that the H5N1 viruses could vertical transmit to the fetus through the placenta in the BALB/ c mouse model, and the viruses could partly be evacuated by the pregnant mice during abortion or preterm delivery. This study may further our understanding about the transmission of this highly pathogenic avian influenza viruses, supply optimized clinical treatment method for pregnant women, and shed some light on better preventing and controlling for future potential outbreak of H5N1 influenza pandemic.
\end{abstract}

\section{Findings}

Influenza A viruses belong to Orthomyxoviridae and consist of segmented, negative-sense RNA genomes. The known subtypes of influenza A viruses include 16 subtypes of hemagglutinin (HA) and nine subtypes of neuraminidase (NA) [1]. During 1997 in Hong Kong, 18 human cases of respiratory illness, including 6 fatalities, were caused by highly pathogenic avian influenza H5N1 viruses [2-4]. The H5N1 infections in humans were preceded by the circulation of $\mathrm{H} 5 \mathrm{~N} 1$ viruses in birds, first in poultry farms and later in wholesale and retail poultry markets in Hong Kong [5]. Concerns that the virus might acquire the ability to efficiently spread between humans have led public health authorities to accelerate preparations for pandemic influenza. The fact that the H5N1 viruses resulted in severe or fatal respiratory disease in the majority of infected persons aged 13 to 60 years was of particular concern since this age group is

\footnotetext{
* Correspondence: qinchuan@pumc.edu.cn

+ Contributed equally

'Institute of Laboratory Animal Sciences, Chinese Academy of Medical Sciences (CAMS) \& Comparative Medicine Center, Peking Union Medical Collage (PUMC), Beijing, 100021, China

Full list of author information is available at the end of the article
}

not normally considered to be at increased risk for death and complications from influenza [6,7].

Pregnant women are at high risk for severe complications of influenza during previous pandemics of 1918 and 1957 [8-10]. Among 1,350 reported cases of influenza among pregnant women during the pandemic of 1918 , the proportion of deaths was reported to be $27 \%$ [9]. Similarly, among a small case series of 86 pregnant women hospitalized in Chicago for influenza in 1918, 45\% died [11]. Among pregnancy-associated deaths in Minnesota during the 1957 pandemic, influenza was the leading cause of death, accounting for nearly $20 \%$ of deaths associated with pregnancy during the pandemic period, half of women of reproductive age who died were pregnant [8]. For the highly pathogenic avian influenza H5N1 virus, a previous healthy pregnant woman at 4 months' gestation died in Anhui Province of China in 2005 since of involved in slaughtering and defeathering sick poultry infected with H5N1 [12]. Furthermore, pregnancy has also been a risk factor for increased illness during interpandemic periods [13]. The increased morbility and mortality are believed to be related to several physiologic changes that occur during pregnancy. Because of mechanical and hormonal alterations that occur during pregnancy, several changes also occur to 
the cardiovascular and respiratory systems, including increased heart rate, stroke volume, oxygen consumption, and decreased lung capacity [14]. Relevant immunologic alterations also occur during pregnancy, with a shift away from cell-mediated immunity toward humoral immunity. This shift can render pregnant women more susceptible to, or more severely affected by, certain viral pathogens, including influenza [15].

Although certain infections are well recognized to increase the risk for influenza-associated illness and death for pregnant women, the effects of abortion and preterm delivery to maternal influenza infection are not well understood. To address this problem, mouse model for $\mathrm{H} 5 \mathrm{~N} 1$ virus infection was established primarily. Briefly, female 5-week-old SPF level BALB/c mice (Institute of Laboratory Animal Sciences, Beijing) were used. Mice were anesthetized and inoculated intranasally with $10^{2} \mathrm{TCID}_{50}$ of $\mathrm{A} /$ Shenzhen/406H/2006 virus strain in a volume of $50 \mu \mathrm{l}$, and were monitored for clinical signs over a 14 day period. Meanwhile, additional inoculated mice were euthanized at 5 days post infection (d.p.i) for assessment of infectious virus in tissues. The procedures were approved by the Institute of Animal Use and Care Committee of the Institute of Laboratory Animal Science, Peking Union Medical College (ILAS-PC-2010006) and all experiments involving the $\mathrm{H} 5 \mathrm{~N} 1$ virus were conducted under biosafety level 3 (ABSL-3) conditions. Two days post challenge, typical clinical symptoms including hunched posture, ruffled fur, loss of appetite began to exhibit. Mice began to die at 5 d.p.i, and all mice died within 8 d.p.i. High titers $\left(\operatorname{TCID}_{50}>10^{6}\right)$ of infectious virus could be detected in lung tissues of infected mice which euthanized at 5 d.p.i, and the RNA copy numbers reached $10^{6}$ per milligram.

Based on this mouse model, two independent experiments were carried out to verify whether the highly pathogenic avian influenza $\mathrm{H} 5 \mathrm{~N} 1$ viruses could vertical transmit to the fetus through the placenta, and the viruses may partly be evacuated by the pregnant women during abortion or preterm delivery.

Firstly, five mice in the second trimesters of pregnancy were intranasally challenged with $\mathrm{H} 5 \mathrm{~N} 1$ virus. Meanwhile, another five nonpregnant mice with the same age were used as control. Five days post challenge, mice were euthanized and lung and placenta from maternal mice and fetuses were collected separately for viral nucleotide material quantification. Results demonstrated that the mean viral nucleotide copy numbers of lung tissues from pregnant mice were significant lower than those from nonpregnant mice $(P<0.05)$. Meanwhile, viral nucleotides could also been detected in the placenta and fetus (Figure 1), although the copy numbers were significant lower than those from maternal lung tissues $(P<0.05)$. All these data

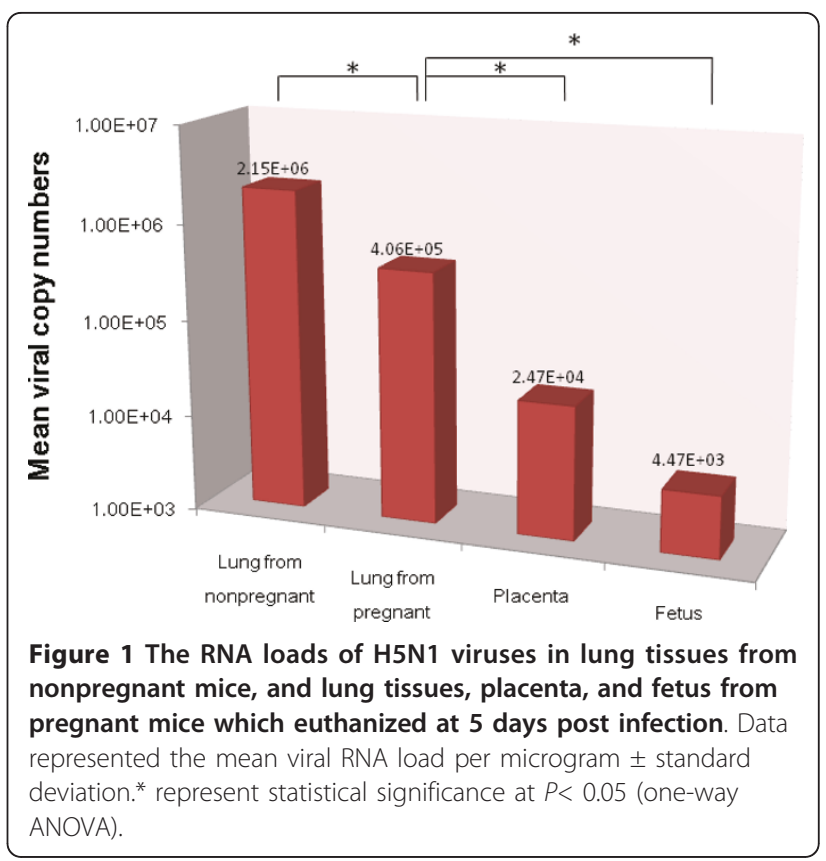

verified that $\mathrm{H} 5 \mathrm{~N} 1$ virus could vertical transmit to the fetus through the placenta, and the virus load in maternal mice could partly be evacuated during abortion.

Secondly, eight mice in the third trimesters of pregnancy were intranasally challenged with $\mathrm{H} 5 \mathrm{~N} 1$ virus, and each pregnant mouse delivered 5 to 7 neonates the next day post infection. Meanwhile, another fourteen nonpregnant mice with the same age were used as control. All mice were monitored daily for mortality up to 14 d.p.i. Results showed that although all adult mice died within 14 days (Figure 2), the mean survival days of pregnant mice were longer compared with those nonpregnant (Figure 3). Meanwhile, results showed that $12.5 \%$ neonates survived up to 14 days (Figure 2). However, since the neonates born the next day post the

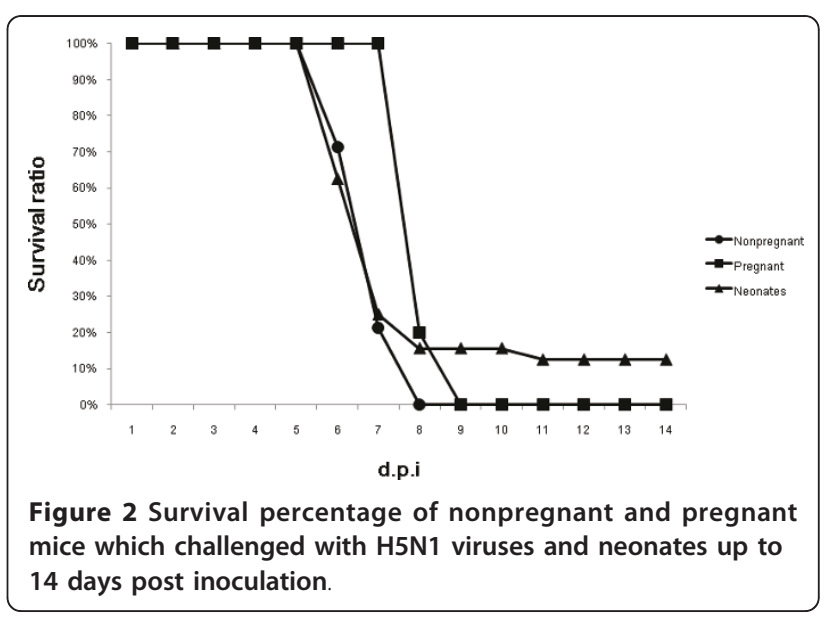




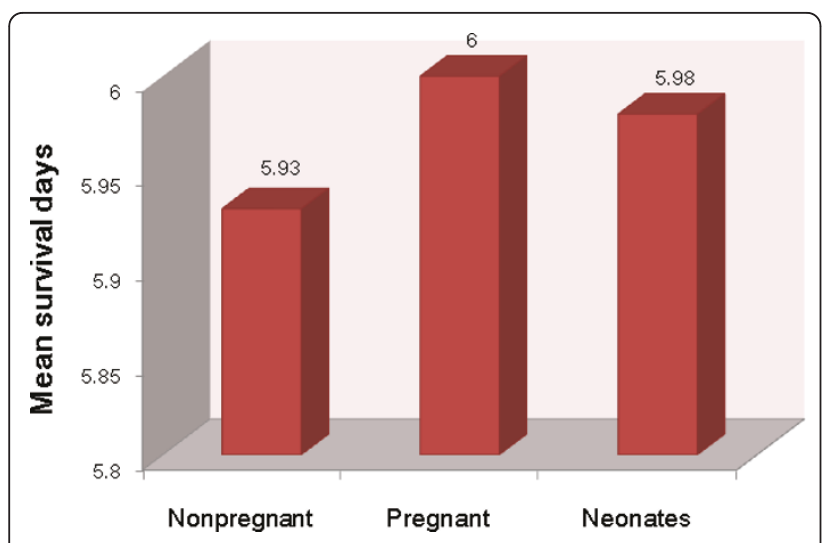

Figure 3 The mean survival days of nonpregnant, pregnant, and infant mice which challenged with H5N1 viruses.

maternal mice were challenged, whether the H5N1 viruses were transmitted to neonates through the placenta, or aerosol, or breastfeeding was unknown and needs further research.

All above data based on mouse model probably proposed that the H5N1 viruses could vertical transmit to the fetus through the placenta, and the viruses may partly be evacuated by the pregnant women during abortion or preterm delivery. However, these primary findings need to be confirmed by further studies, especially clinical cases monitor and observation. If this phenomenon was proven to be similar in human, it may further our understanding about the transmission of this highly pathogenic avian influenza viruses, supply optimized clinical treatment method for pregnant women, and shed some light on better preventing and controlling for future potential outbreak of H5N1 influenza pandemic.

\section{Acknowledgements}

This work was supported by the National Science and Technology Major Projects of Infectious Disease (2009ZX10004-016 and 2009ZX10004-402), the Industry Foundation of the Ministry of Health (200802036), and Open Fund of the Key Laboratory of Human Diseases Comparative Medicine, Ministry of Health (DWS201112).

\begin{abstract}
Author details
IInstitute of Laboratory Animal Sciences, Chinese Academy of Medical Sciences (CAMS) \& Comparative Medicine Center, Peking Union Medical Collage (PUMC), Beijing, 100021, China. ${ }^{2}$ Key Laboratory of Human Disease Comparative Medicine, Ministry of Health, Beijing, 100021, PR China.
\end{abstract}

\section{Authors' contributions}

LLX carried out the animal challenge and observation, real-time PCR, statistical analysis and drafted the manuscript. LLB participated in the animal experiments. WD performed pathological analysis. CQ predicated in the design of the study. All authors read and approved the final manuscript.

\section{Competing interests}

The authors declare that they have no competing interests.

Received: 28 January 2011 Accepted: 8 July 2011 Published: 8 July 2011

\section{References}

1. Cheung TK, Poon LL: Biology of influenza a virus. Ann N Y Acad Sci 2007, 1102:1-25

2. Subbarao K, Klimov A, Katz J, Regnery H, Lim W, Hall H, Perdue M, Swayne D, Bender C, Huang J, Hemphill M, Rowe T, Shaw M, Xu X, Fukuda K, Cox N: Characterization of an avian influenza A (H5N1) virus isolated from a child with a fatal respiratory illness. Science 1998, 279:393-396

3. Claas EC, Osterhaus AD, van Beek R, De Jong JC, Rimmelzwaan GF, Senne DA, Krauss S, Shortridge KF, Webster RG: Human influenza A H5N1 virus related to a highly pathogenic avian influenza virus. Lancet 1998, 351:472-477.

4. de Jong JC, Claas EC, Osterhaus AD, Webster RG, Lim WL: A pandemic warning? Nature 1997, 389:554

5. Shortridge KF, Zhou NN, Guan Y, Gao P, Ito T, Kawaoka Y, Kodihalli S, Krauss S, Markwell D, Murti KG, Norwood M, Senne D, Sims L, Takada A Webster RG: Characterization of avian H5N1 influenza viruses from poultry in Hong Kong. Virology 1998, 252:331-342.

6. $Y u$ H, Gao Z, Feng Z, Shu Y, Xiang N, Zhou L, Huai Y, Feng L, Peng Z, Li Z, Xu C, Li J, Hu C, Li Q, Xu X, Liu X, Liu Z, Xu L, Chen Y, Luo H, Wei L, Zhang X, Xin J, Guo J, Wang Q, Yuan Z, Zhang K, Zhang W, Yang J, Zhong X, Xia S, Li L, Cheng J, Ma E, He P, Lee SS, Wang Y, Uyeki TM, Yang W: Clinical characteristics of 26 human cases of highly pathogenic avian influenza A (H5N1) virus infection in China. PLoS One 2008, 3:e2985.

7. Yuen KY, Chan PK, Peiris M, Tsang DN, Que TL, Shortridge KF, Cheung PT, To WK, Ho ET, Sung R, Cheng AF: Clinical features and rapid viral diagnosis of human disease associated with avian influenza A H5N1 virus. Lancet 1998, 351:467-471.

8. Freeman DW, Barno A: Deaths from Asian influenza associated with pregnancy. Am J Obstet Gynecol 1959, 78:1172-1175.

9. Harris J: Influenza occurring in pregnant women. JAMA 1919, 72:978-980

10. Greenberg M, Jacobziner H, Pakter J, Weisl BA: Maternal mortality in the epidemic of Asian influenza, New York City, 1957. Am J Obstet Gynecol 1958, 76:897-902.

11. Nuzum JW, Pilot I, Stangl FH, Bonar BE: 1918 pandemic influenza and pneumonia in a large civil hospital. IMJ III Med J 1976, 150:612-616.

12. Shu Y, Yu H, Li D: Lethal avian influenza $A(H 5 N 1)$ infection in a pregnant woman in Anhui Province, China. N Engl J Med 2006, 354:1421-1422.

13. Neuzil KM, Reed GW, Mitchel EF, Simonsen L, Griffin MR: Impact of influenza on acute cardiopulmonary hospitalizations in pregnant women. Am J Epidemiol 1998, 148:1094-1102.

14. Goodnight WH, Soper DE: Pneumonia in pregnancy. Crit Care Med 2005, 33:S390-397.

15. Jamieson DJ, Theiler RN, Rasmussen SA: Emerging infections and pregnancy. Emerg Infect Dis 2006, 12:1638-1643.

doi:10.1186/1743-422X-8-342

Cite this article as: $\mathrm{Xu}$ et al:: Highly pathogenic avian influenza $\mathrm{H} 5 \mathrm{~N} 1$ virus could partly be evacuated by pregnant BALB/C mouse during abortion or preterm delivery. Virology Journal 2011 8:342.

\section{Submit your next manuscript to BioMed Central and take full advantage of:}

- Convenient online submission

- Thorough peer review

- No space constraints or color figure charges

- Immediate publication on acceptance

- Inclusion in PubMed, CAS, Scopus and Google Scholar

- Research which is freely available for redistribution 